\title{
A cross-sectional study of socio-demographic and clinical profile of HIV patients at ART plus centre, Sawai Man Singh Hospital, Jaipur, India
}

\author{
Charu Jain ${ }^{1}$, Lokendra Sharma ${ }^{1}$, Uma Advani ${ }^{1}$, Munesh Kumar² ${ }^{2}$, Amit Tak $^{3}$, Monica Jain ${ }^{1}$
}

\begin{abstract}
Background: This study aimed to understand the regional variation in the socio-demographic and clinical profile of human immunodeficiency virus (HIV) infected patients at antiretroviral therapy plus centre of Sawai Man Singh (SMS) hospital, Jaipur, India.

Methods: A descriptive cross-sectional study was conducted on HIV patients from January to December 2019. The HIV-positive patients of all age groups and all categories were included in the study. The socio-economic status was assessed by BG Prasad classification-based consumer price index. However, the clinical staging was done according to the World Health Organization (WHO) classification of HIV/AIDS. Data were expressed as mean \pm standard deviation.

Results: Among 525 HIV patients $59.16 \%$ were males, $40.26 \%$ females and $0.57 \%$ intersex. About half $(51.0 \%)$ in the reproductive age group with mean age $36 \pm 13$ years. The commonest mode of HIV transmission was heterosexual $(89.77 \%)$. Maximum belonged to social class I (57.84\%) and class II (26.05\%) of BG Prasad's socioeconomic status. Each of the non-agricultural laborers and semi-skilled workers constitutes $18.0 \%$, and the housewives were $23.6 \%$. At the time of presentation, baseline CD4+Tcell count was $<350 / \mathrm{mm} 3$ in $55.0 \%$ of HIV patients. Pulmonary tuberculosis and skin involvement were the most predominant secondary opportunistic infections accounting for $24.8 \%$ and $7.8 \%$, respectively. More than half $(52.09 \%)$ of patients were in WHO clinical stage I of HIV disease.
\end{abstract}

Conclusion: Socio-demographic and clinical profile of study participants reflect an impact of early case detection and timely institution of highly active antiretroviral therapy.

Keywords: Clinical Profile HIV, Socio-demographic Profile HIV, Opportunistic Infection, Antiretroviral Therapy, India

\section{Background}

Acquired immunodeficiency syndrome is a chronic, potentially life-threatening condition caused by the human immunodeficiency virus. It harms the immune system by destroying white blood cells such as CD4+ T cells (T-helper cells), dendritic cells, and macrophages. As the number of clusters of differentiation 4 (CD4+) cells in the body decreases, the immune system gets collapsed and leads to the risk of developing opportunistic infections and certain malignancies. According to the Joint United Nations Program on HIV/AIDS and World Health Organization Report 2020, around 38 million people are living with HIV/AIDS worldwide, some 1.7 million people were newly infected with the virus, and 690 thousand people died of HIV related illness in 2019 [1].

*Correspondence: manuluvly@gmail.com

2Department of Medicine, RUHS college of medical sciences, Jaipur, India Full list of author information is available at the end of the article
India has the third-highest burden of HIV in the world. It is estimated by the annual report 2018-2019 published by the Department of Health and Family Welfare, Government of India, that the total number of People Living with HIV (PLHIV) in India is 21.40 lakhs (lakh is a unit in the Indian numbering system equal to one hundred thousand). An estimated 87 thousand new HIV infections and 69.11 thousand people died of AIDS-related causes nationally in 2017 [2]. National adult HIV prevalence in India is estimated at $0.22 \%(0.16 \%-0.30 \%)$ with range of $0.25 \%$ among males and $0.19 \%$ among females. Rajasthan is among the States /UTs, having less than 1 lakh people living with HIV with a prevalence lesser than the national average [3]. HIV/AIDS is one of the most severe socioeconomic concerns because most of the affected population is from economically productive age group and occurring in sexually active persons with high-risk behavior. The World Bank has categorized India as a low-income country. Approximately $70.0 \%$ of its people live in rural areas. 
The critical factors responsible for the disease's spread are ignorance about the disease, fear of discrimination, and consequent avoidance for testing and treatment. Females do not seek medical care in fear of eviction, making them more vulnerable to the disease. The most common occupation group infected with HIV is the labor group, including the skilled and semi-skilled workers and agricultural laborers, truck drivers, and local transport workers. The reason behind their infection is moving to the metropolitan cities, staying away from their spouse for more extended periods, having poor awareness, and lower literacy. India launched its free national antiretroviral therapy program in April 2004, which is the cornerstone of managing patients with HIV/AIDS infection. Opportunistic infections (OI) are becoming a predominant cause of morbidity even with ART's widespread use and prophylaxis to these infections. Tuberculosis (TB) is the most reported OI among HIV-infected patients in India. Oral candidiasis, diarrhea, pneumocystis Jiroveci Pneumonia, herpes simplex, herpes zoster, respiratory and skin bacterial infections, cryptococcal meningitis, cytomegalovirus retinitis are other commonly reported OIs [4,5]. There is regional variation in the demographic and clinical presentation of HIV disease and the spectrum of opportunistic infections of HIV patients. Under this background, we studied the socio-demographic and clinical profile of HIV patients.

\section{Methods}

A descriptive cross-sectional study was conducted at antiretroviral therapy (ART) plus the centre of Sawai Man Singh (SMS) Hospital Jaipur, Rajasthan, India, from January to December 2019. The ART plus center was established on 05 October 2005, occupying 2750 yards with complete diagnostic (hematological and radiological) workup facilities for all PLHIV free of cost. ART plus the centre of SMS Hospital is affiliated with The National Aids Control Organization (NACO) and has facilities for first-line ART, alternate first line, second line, third line ART, and drugs for managing all opportunistic infections along with trained staff for counseling and management of HIV patients.

\section{Inclusion and exclusion criteria}

The HIV-positive patients on highly active antiretroviral therapy (HAART) were randomly selected based on inclusion and exclusion criteria. HAART is a "treatment regimen typically comprised of a combination of three or more antiretroviral drugs therapy". The HIV-positive patients of all age groups and all categories were included in the study. Those with missing data and not willing to give consent were excluded from the study. Enrolled HIV patients were studied for demographic details including age, sex, residence, education level, occupation, socio-economic status, marital status, HIV status of spouse, mode of transmission, and for clinical profile including presenting symptoms, WHO clinical stage, CD4 count, opportunistic infections at the time of presentation and ART regimen.

Socio-economic status and clinical staging of the patients The Socio-economic status was assessed by the BG prasad classification-based consumer price index [6]. It applies to both urban and rural populations. It is based on per capita monthly income and is widely used in India. According to the World Health Organization (WHO), clinical staging of the patients was done according to the World Health Organization (WHO) classification of HIV/AIDS [7]. HAART therapy was given to the patients by the Doctor of ART centre, depending on eligibility as per NACO guidelines. The patients were given ART regardless of their $\mathrm{CD} 4$ count under the new ART guidelines [7].

\section{Sample size calculation}

The sample size was calculated for $95 \%$ confidence limit, $80.0 \%$ power and $8.5 \%$ relative error as per previous studies [8], giving the final sample of $525 \mathrm{HIV}$ cases.

\section{Statistical analysis}

The descriptive statistics of quantitative data were expressed as mean and standard deviation. The association between qualitative attributes was estimated with a coefficient of contingency $(\mathrm{C})$. The value of ' $\mathrm{C}$ ' varies from 0 to 1 (for an infinite number of classes). There is no strength of association when the coefficient of contingency is zero $(\mathrm{C}=0)$. The baseline CD4 count was divided into three categories: baseline level less than $350 / \mu 1$, baseline level between $350-500 / \mu 1$, and baseline level greater than $500 / \mu 1$. The associations of baseline CD4 categories with opportunistic infections were analyzed. Statistical significance was tested with Chi-square tests at a 5\% level of significance $(\alpha=0.5)$. The JASP 0.11 .1 .0 statistical package was used for statistical analysis.

\section{Results}

A total of 525 patients were enrolled in this study with a mean age of $36 \pm 13$ years. More than half $(59.16 \%)$ of participants were males, married $(81.13 \%)$, primary school education (60.66\%). According to BG Prasad Score, more than half (57.84\%) of participants from the socio-economic Status I. Heterosexual mode of HIV/AIDS transmission prominent among 89.77 of the studied sample (Table 1).

The leading age group affected with HIV/AIDS was from the reproductive age group that is $21-40$ years $(51.0 \%)$, and $11.26 \%$ of patients belonged to the pediatric age group, as shown in figure 1(a). ART centre of SMS Hospital, Jaipur, caters to HIV patients not only from the native state of Rajasthan $(92.0 \%)$ but also from border states of Haryana (2.4\%) and Uttar Pradesh (UP) (2.6\%) and other states like Delhi, Bihar, and MP Among the districts of Rajasthan apart from Jaipur district (45.0\%), HIV patients attended ART centre were residential from Tonk (12.0\%), Dholpur (9.0\%), Karauli (7.6\%), Sikar (7.4 \%), Sawai Madhopur (7.2\%), Dausa (4.0\%) and Alwar (2.0\%) as shown in figure 1(b).

The commonest mode of transmission was the heterosexual route $(89.7 \%)$. Among $81.0 \%$ married HIV patients, spouses of $53.4 \%$ were found HIV positive. In contrast, vertical transmission (mother to child) accounted for $(6.74 \%)$ cases of HIV transmission. Considering the occupation of HIV patients, the highest percent was among the housewives (24.0\%), nonagricultural laborers (19.0\%), and skilled workers (19.0\%) respectively. However, lowest percent found among the students $(8.0 \%)$, local transport workers $(7.0 \%)$, and truck drivers $(6.0 \%)$ respectively. 
Table 1 Demographic characteristics of patients with HIV/AIDS $(n=525)$

\begin{tabular}{|c|c|c|c|}
\hline Variables & Categories & $\mathbf{N}$ & $\%$ \\
\hline \multirow[t]{4}{*}{ Age group } & $0-20$ & 59 & 11.26 \\
\hline & $21-40$ & 268 & 51.14 \\
\hline & $41-60$ & 175 & 33.40 \\
\hline & $\geq 60$ & 22 & 4.20 \\
\hline \multirow[t]{3}{*}{ Gender } & Female & 211 & 40.27 \\
\hline & Intersex & 3 & 0.573 \\
\hline & Male & 310 & 59.16 \\
\hline \multirow[t]{4}{*}{ Marital status } & Divorced & 15 & 4.05 \\
\hline & Married & 301 & 81.13 \\
\hline & Single & 37 & 9.97 \\
\hline & Widow & 18 & 4.85 \\
\hline \multirow[t]{5}{*}{ Educational status } & College & 83 & 17.01 \\
\hline & Illiterate & 45 & 9.22 \\
\hline & Primary & 296 & 60.66 \\
\hline & Secondary & 58 & 11.89 \\
\hline & Senior Secondary & 6 & 1.23 \\
\hline \multirow{7}{*}{$\begin{array}{l}\text { Socio-economic } \\
\text { Status (BG Prasad } \\
\text { Score) }\end{array}$} & I & 273 & 57.84 \\
\hline & & & \\
\hline & & & \\
\hline & II & 123 & 26.06 \\
\hline & III & 66 & 13.98 \\
\hline & IV & 4 & 0.85 \\
\hline & $\mathrm{V}$ & 6 & 1.27 \\
\hline \multirow[t]{6}{*}{ Mode of transmission } & Heterosexual & 386 & 89.77 \\
\hline & Homosexual & 11 & 2.56 \\
\hline & Intravenous Drug & 4 & 0.93 \\
\hline & Use & & \\
\hline & Mother to Child & 29 & 6.74 \\
\hline & Blood transfusion & Nil & Nil \\
\hline
\end{tabular}

Clinical profile of HIV/AIDS patients shows that $56.0 \%$ were having baseline CD4 count $<350 / \mu 1$ while $44.0 \%$ were having CD 4 count between $>350 / \mu 1$. Most of the patients belonged to WHO clinical stage I (52.0\%) and stage II (28.0\%). More than half $(55.3 \%)$ were asymptomatic at presentation. The most frequent presenting symptoms were fever, weight loss and cough $(22.1 \%)$, persistent diarrhea, oral candidiasis, and generalized weakness, which accounted for $4.7 \%, 11.26 \%$, and $3.8 \%$, respectively, as shown in figure 2(a). Furthermore, HIV/AIDS patients also reported having secondary opportunistic infections at the time of presentation (38.55\%), among which pulmonary tuberculosis and skin involvement were more predominant, accounting for $24.8 \%$ and $7.8 \%$, respectively shown in figure 2 (b).

As per NACO guidelines, all eligible patients were given antiretroviral therapy, which included a standard first-line regimen:

(i) Tenofovir (TDF $300 \mathrm{mg}$ ) + Lamivudine (3TC $300 \mathrm{mg})+$ Efavirenz (EFV $600 \mathrm{mg}$ ) (TLE) as Fixed Dose Combination (FDC) in a single pill once a day.

OR

Zidovudine (ZDV $300 \mathrm{mg}$ ) +Lamivudine (3TC $150 \mathrm{mg}$ ) + Nevirapine (NVP $200 \mathrm{mg}$ ) / Efavirenz (EFV $600 \mathrm{mg}$ ). The zidovudine-based regimen was given to those patients who were initiated earlier in the program.

OR

Abacavir + Lamivudine + Efavirenz / Abacavir+ Lamivudine + Nevirapine, mainly given in pediatric patients.

(ii) Trimethoprim-Sulfamethoxazole prophylaxis was given to prevent Pneumocystis Carinii pneumonia in all patients with a CD4 lymphocyte count of $<350$ cells $/ \mu$ l. Isoniazid prophylaxis was given to all new patients till 2-3 weeks of ART. In the case of patients who developed resistance to these first-line regimens (clinical failure, immunological failure, or virological failure) were switched to second-line antiretroviral therapy, containing boosted protease inhibitors (PI), e.g., Atazanavir / Ritonavir or Lopinavir/ Ritonavir combination.

Tuberculosis, oral candidiasis, and encephalitis found a significant inverse correlation $(P<0.05)$ with baseline CD4 count. Pneumocystis pneumonia, Toxoplasmosis, and malignancies develop late in the illness, so not having a positive correlation ( $\mathrm{p}<0.05$ ) with baseline CD4 count (Table 2 ).

\section{Discussion}

The database search retrieved six citations. There were no duplicates. Four articles not matching the eligibility criteria were excluded. The adjunct search in the bibliography of the reviewed trials did not reveal any additional articles. Figure 1 demonstrates the study selection process. In this systematic review, we included two RCTs matching the above inclusion criteria. These trials sourced data from about 833 COVID-19 patients from 115 hospitals in Asia, Europe, and the US [15,16]. In both the trials, the patients received the intravenous remdesivir of $200 \mathrm{mg}$ on the first day and $100 \mathrm{mg}$ on the successive nine days $[15,16]$. In one trial, some participants received the regimen for five days (instead of 10 days) [16]. The comparator arm received a placebo and standard care in the respective trials $[15,16]$. Table 1 presents the salient features of these trials.

Table 2 Association between baseline CD4 and other attributes are calculated with a coefficient of contingency.

\begin{tabular}{|c|c|c|c|c|}
\hline & $\begin{array}{l}\text { Opportunistic } \\
\text { Infection }\end{array}$ & $\begin{array}{l}\text { Chi- } \\
\text { square }\end{array}$ & $\begin{array}{l}\text { Coefficient } \\
\text { of } \\
\text { Contingency }\end{array}$ & $\begin{array}{l}P \text { - } \\
\text { value }\end{array}$ \\
\hline \multirow{13}{*}{$\begin{array}{l}\text { Baseline } \\
\text { CD4 } \\
\text { Count }\end{array}$} & Tuberculosis & 10.82 & 0.142 & 0.004 \\
\hline & Skin Infections & 2.76 & 0.072 & 0.251 \\
\hline & Oral & 6.91 & 0.114 & 0.032 \\
\hline & Candidiasis & & & \\
\hline & Bacterial & 2.38 & 0.067 & 0.304 \\
\hline & Pneumonia & & & \\
\hline & Encephalitis & 7.22 & 0.117 & 0.027 \\
\hline & & & & \\
\hline & & & & \\
\hline & Diarrhea & 3.28 & 0.079 & 0.194 \\
\hline & Toxoplasmosis & 2.44 & 0.068 & 0.295 \\
\hline & Malignancies & 2.25 & 0.065 & 0.325 \\
\hline & Tuberculosis & 10.82 & 0.142 & 0.004 \\
\hline
\end{tabular}




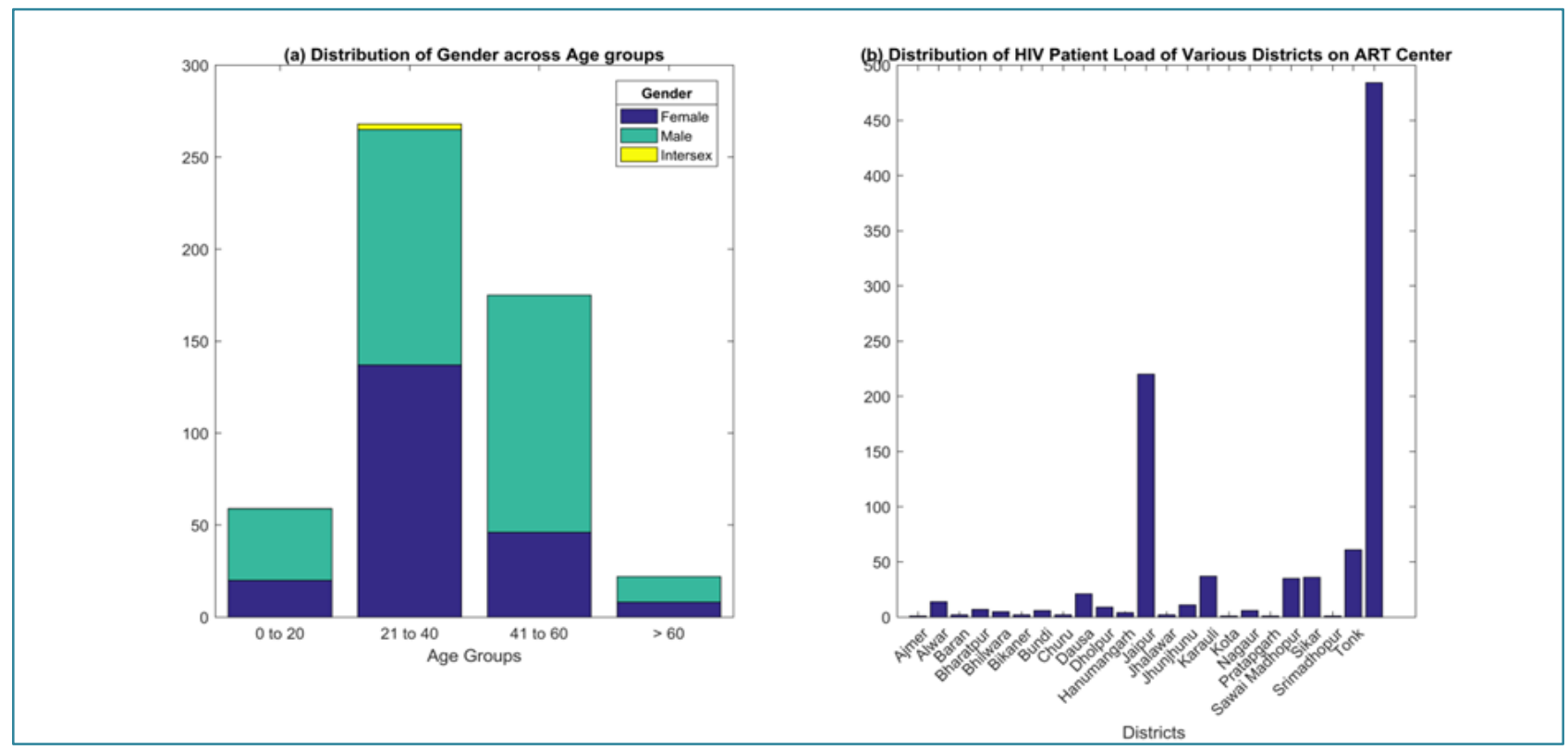

Figure 1 Frequency distribution of demographic characteristics of HIV/AIDS patients (a) Stacked bar graph shows distribution of gender across various age groups. (b) Bar graph shows distribution of HIV/AIDS cases across various districts in the state of Rajasthan.
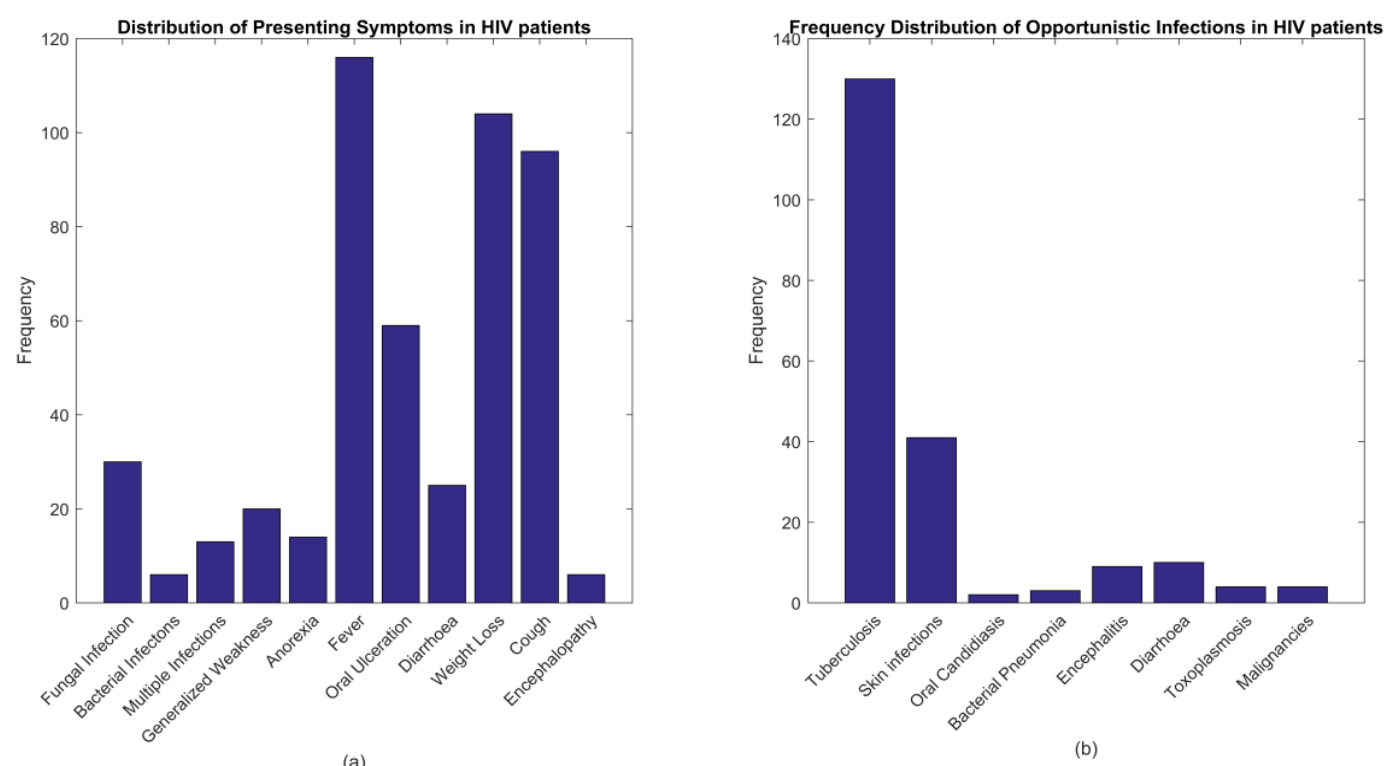

(b)

Figure 2 Frequency distribution of clinical characteristics of HIV/AIDS patients (a) Bar graph shows distribution of presenting symptoms (b) Bar graph shows distribution of opportunistic infections

\section{Discussion}

In our study, the mean age of HIV patients was $36 \pm 13$ years, with male predominance $(59 \%)$. These findings are like the study conducted at SP Medical College Bikaner Rajasthan [8], in which the mean age of HIV patients was $36.64 \pm 12.25$ years, with a male population $(57.66 \%)$ outnumbered in the study. Another study was done at Sardar Valabhbai Patel Hospital, Meerut in western UP [9] found the results at par with our study. In our study, $51.0 \%$ of patients were in the reproductive age group (21-40), while the study conducted at the Institute of Medical Sciences, Banaras Hindu University, Varanasi [10] found that $78.0 \%$ of patients were in this age group. The heterosexual route was the commonest mode of transmission of $\mathrm{HIV}$ infection. These findings were remarkably similar to most previous studies conducted on the socio-demographic profile of HIV patients [8-12]. Emphasizing that if specific measures are applied like encouraging people to adopt and maintain risk reduction strategies, including condom use, adherence to HIV treatment, and sterile injection practices, it can decrease HIV transmission as per cited on HIV gov [11]. A female spouse was found more vulnerable to HIV infection than a male spouse from their partner. Similar findings seen in the study conducted in a rural tertiary care hospital in Maharashtra [12], wherein the spouse positivity was higher among females. These observations could be because in females, a larger surface is exposed, and semen contains a higher concentration of HIV than vaginal or cervical fluids. In our study majority of patients belonged to social class I. However, they were in social class I, and the draw per capita monthly income around 7000-8000, 
contradictory to the study conducted at rural tertiary care hospital Maharashtra [12], in which most patients belonged to social class III \& IV (modified B.G Prasad's social classification). The education of HIV patients in our study found that $90 \%$ of patients were literate, and only $9.8 \%$ were illiterate. Among literates, the maximum number of patients $(60.65 \%)$ were educated only up to the primary level, while a study was done at Lok Nayak hospital, New Delhi [13] found that a total of $82.0 \%$ of HIV patients were literate and only $16.0 \%$ had primary level of education. Therefore, it is inferred that the education level should be raised adequately to obtain knowledge for HIV protection.

The overall spectrum of opportunistic infection in our study is similar to previous studies done at the Institute of Medical Sciences, Banaras Hindu University, Varanasi [10], and at Gauhati Medical College [14]. However, the percentage of the patients with tuberculosis, candidiasis, and diarrhea were lesser when compared to above mentioned studies. Nevertheless, tuberculosis was the most common opportunistic infection in the present study, which matches with studies done in other parts of India [8-15]. In our country, where tuberculosis is endemic, many people are infected with TB in childhood. The immune system breaks down, as in HIV, tuberculosis becomes active. Severe or recurrent skin infections like warts, dermatophytosis, pruritic dermatitis, and herpes zoster or shingles presenting with localized pain and burning sensation followed by vesicle eruption, oropharyngeal candidiasis, or oral thrush (caused by a common yeast fungus, presents with soreness and redness with a white plaque on the tongue, back of the mouth or on throat), chronic diarrhea and severe weight loss were another OI in our study.

It was found that candida esophagitis, cryptococcus meningitis, and parasitic infections such as pneumocystis carinii pneumonia or toxoplasma gondii encephalitis tend to occur when CD4 cell count has dropped to around 100. The present study shows that $45.0 \%$ of our patients were diagnosed through clinical symptoms, while $55.0 \%$ of patients were asymptomatic at the time of presentation and were diagnosed during routine scanning or came for testing due to high-risk behavior. Most of the patients were in WHO clinical stage I (52.0\%) and II (28.6\%), which means most patients in the study were at a relatively good immune status and in the early stage of the disease. This shows an impact of early case detection and timely institution of highly active antiretroviral therapy (HAART). These findings are similar to the study done in Lok Nayak hospital in New Delhi [13] but contradictory to the study done in the rural tertiary care hospital in Maharashtra state [12], where $42.5 \%$ of patients were in stage III.

A previous study at Clinical Hospital Doutor Serafim de Carvalho, Southwestern Goias, Brazil [16] found the mean age of presentation was $39.5 \pm 11$ with male predominance, heterosexual route as a common mode of transmission in HIV patients, these findings were in concordance with our study. This study also [16] found pneumonia caused by Pneumocystis jirovecii was the most predominant OI, while in our study, tuberculosis was common OI among HIV patients. Our study's limitation was that it was conducted at a single tertiary care center with limited sample size. A multi-centric study on a large population is warranted for validation of results.

\section{Conclusion}

Most of the patients were from the reproductive age group, semi-skilled workers, and truck drivers and had a primary education level. Our study also found that most of the patients were asymptomatic at the time of presentation, and the majority of the patients were in WHO clinical stage I and II at the time of presentation, with a lesser number of patients were affected with an opportunistic infection this reflects an impact of early case detection and timely institution of highly active antiretroviral therapy (HAART). The study recommends the importance of accurate information about disease prevention, especially among spouses of affected patients and people with high-risk behavior. The study's data will help health care professionals for effective case management and policymaking for the institution.

\section{Abbreviation}

HIV: Human Immunodeficiency Virus; NACO: National AIDS control organization; WHO: World health organization; OI: Opportunistic infection; ART: Antiretroviral Therapy; TB: Tuberculosis; PLHIV: People Living with HIV; HAART: Highly Active Antiretroviral Drugs; CD4: Cluster of Differentiation 4; UP: Uttar Pradesh

\section{Declaration}

\section{Acknowledgment}

The authors would like to acknowledge NACO for their permission to carry out the study. The authors would also like to acknowledge the doctors and staff of ART Centre of SMS Hospital, Jaipur, India, and all the patients who participated in the study.

\section{Funding}

The author received no financial support for the research, authorship, and/or publication of this article.

\section{Availability of data and materials}

Data will be available by emailing jaincharujaincharu2007@gmail.com

\section{Authors' contributions}

Authors have contributed equally to the study concept, design, writing of the original draft. Amit Tak participated in the statistical analysis of the data. Monika Jain reviewed and edited the manuscript. All authors read and approved the final manuscript.

\section{Ethics approval and consent to participate}

We researched the Declaration of Helsinki, and the protocol was approved by the institutional ethics committee (IEC 4122/MC/EC/2018, dated 9/10/18) SMS. Medical College Jaipur, Rajasthan, India.

\section{Consent for publication}

Not applicable

\section{Competing interest}

The authors declare that they have no competing interests.

\section{Open Access}

This article is distributed under the terms of the Creative Commons $\begin{array}{llll}\text { Attribution } & 4.0 & \text { International }\end{array}$ (http://creativecommons.org/licenses/by/4.0/), which permits unrestricted use, distribution, and reproduction in any medium, provided you give appropriate credit to the original author(s) and the 
source, provide a link to the Creative Commons license, and indicate if changes were made. The Creative Commons Public Domain Dedication waiver (http://creativecommons.org/publicdomain/zero/1.0/) applies to the data made available in this article, unless otherwise stated.

\section{Author details}

${ }^{1}$ Department of Pharmacology, SMS Medical College, Jaipur, India. ${ }^{2}$ Department of Medicine, RUHS college of medical sciences, Jaipur, India. ${ }^{3}$ ICMR- National centre for disease informatics and research, Bengaluru, India.

Article Info

Received: 28 November 2020

Accepted: 02 February 2021

Published: 21 March 2021

\section{References}

1. UNAIDS. Global report: UNAIDS report on the global AIDS epidemic. Geneva: Joint United Nations Programme on HIV/AIDS (UNAIDS), 2020.

2. National AIDS Control Organisation, Department of AIDS Control. Annual Report 2018-2019. New Delhi: Ministry of Health \& Family Welfare.

3. National AIDS Control Organization (2017). HIV Sentinel Surveillance: Technical Brief, India 2016-17. New Delhi: NACO, Ministry of Health and Family Welfare, Government of India. Available

from:http://naco.gov.in/sites/default/files/HIV\%20SENTINEL\%2 OSURVEILLANCE_06_12_2017_0.pdf

4. Rathee R, Atri S, Chaudhary A. Spectrum of opportunistic infections in HIV seropositive patients at the art centre, PGIMS, Rohtak. International Journal of Contemporary Medical Research 2017;4(5):1219-1222.

5. Sirohi P, Gupta A, Gupta S. Profile of opportunistic infections among HIV patients prior to starting ART in a tertiary care teaching hospital in Rajasthan. RUHS Journal of health sciences 2019; 4(2): 85-89. http://dx.doi.org/10.37821/ruhsjhs.4.2.2019.8589

6. Pandey VK, Aggarwal P, Kakkar R. Modified BG Prasad Socioeconomic Classification, Update - 2019. Indian journal of community health.2019; 31(01):123-125. Available from: https://www.iapsmupuk.org/journal/index.php/IJCH/article/view/1 055
7. National AIDS Control Organization \& ICMR-National Institute of Medical Statistics (2018). HIV Estimations 2017: Technical Report. New Delhi: NACO, Ministry of Health and Family Welfare, Government of India. Available from: http://naco.gov.in/sites/default/files/HIV\%20Estimations\%202017 \%20Report_1.pdf

8. Kumawat S, Kochar A, Sirohi P, Garhwal J. Socio-demographic and clinical profile of HIV/AIDS patients in HAART era at a tertiary care hospital in North-West Rajasthan, India. Int J Community Med Public Health.2016;3(8):2088-2093. http://dx.doi.org/10.18203/2394-6040.ijcmph20162551

9. Yadav MK, Sharma J, Tungvir AS, Trivedi A, Khosla B. A CrossSectional Study on Clinico-epidemiological Profile of HIV Positive Patients attending ART Centre at a Tertiary Care Hospital of Western Uttar Pradesh. Natl J Med Res.2014; 4(4): 366-369.

10. Chakravarty J, Mehta H, Parekh A, Attili SVS, Agrawal NR, Singh SP, et al. Study on clinico-epidemiological profile of HIV patients in eastern India. November 2006; 54: 854-857 https://www.researchgate.net/publication/6554486

11. HIV.gov. Available from: https://www.hiv.gov/ [Accessed on 11 September 2020].

12. Deshpande JD, Giri PA, Phalke DB. Clinico-epidemiological profile of HIV patients attending ART centre in rural Western Maharashtra, India. southeast Asia Journal of Public Health 2012; 2(2):16-21. https://doi.org/10.3329/seajph.v2i2.15938

13. Jha AK, Chadha S, Uppal B, Bhalla P, Kishore J, Dewan R. Socio-demographic and immunological profile of HIV patients attending ART clinic in a tertiary care hospital in North India. J HIV Clin Scientific Res.2014; 1(1): 007-010. https://doi.org/10.17352/2455-3786.000002

14. Boruah PK, Adhikari AK. Clinical spectrum of HIV/AIDS presenting to Gauhati Medical College. J Assoc Physicians India. 2003; 51:1258-60.

15. Nair SP, Moorty KP, Suprakasan S. Clinico-epidemiological study of HIV patients in Trivandrum. Ind $\mathrm{J}$ Dermatol VenereolLeprol.2003;69:100-3.

16. 16.Guimarães Dias RF, Bento LO, Tavares C, Filho HR, Cesário da Silva MA, Moraes LC, et al. Epidemiological and clinical profile of HIV-infected patients from Southwestern Goias State, Brazil. Rev. Inst. Med. trop. S. Paulo.2018; 60:1678-9946. https://doi.org/10.1590/s1678-9946201860034 